\title{
O "Currículo Paralelo" dos Estudantes de Medicina da Universidade Federal de Minas Gerais
}

\section{The "Parallel Curriculum" of Medical Students of the Federal University of Minas Gerais (UFMG)}

Ari de Pinho Tavares ${ }^{1}$ Roberto Assis Ferreira ${ }^{1}$ Elisabeth Barboza França ${ }^{1}$ Carlos Alfredo Fonseca Junior ${ }^{1}$ Gustavo Coelho Lopes ${ }^{1}$ Nayanne Gama Teixeira Dantas ${ }^{1}$ Séphora Augusta Vieira Cardoso ${ }^{1}$

PALAVRAS-CHAVE:

-Educação Médica;

-Currículo;

-EducaçãoSuperior;

-Escolas Médicas.

KEY-WORDS:

- Education, Medical;

- Curriculum;

- Education, Graduate;

- Schools, Medical,

Recebido em: 04/10/2006

Aprovado em: 28/05/2007

\section{R E S U M O}

As atividades em busca de complementação da formação e aumento da experiência clínica dos alunos de Medicina - eqüidistantes e livres de controles acadêmicos - configuram o chamado "currículo paralelo". O objetivo deste trabalho foi estudar o "currículo paralelo" dos alunos do ciclo profissional do curso médico da Faculdade de Medicina da UFMG, relativo ao primeiro semestre de 2004. Foram entrevistados 232 alunos, por meio de questionário estruturado, com dez seções, que avaliaram as atividades extracurriculares de plantões, enfermarias, ambulatórios, projetos, grupos de estudo, grupos de raciocínio clínico, extensão e publicações. Cada estudante respondeu sobre o período em curso (primeiro semestre de 2004) e sobre o período anterior. Os resultados mostraram que o "currículo paralelo" estava presente para a grande maioria dos alunos, com 82,5\% deles com atividades e uma média de 3,4 por aluno e ocupando, em média, 8,2 horas semanais. A atividade mais presente foi a de extensão, seguida pelas de projetos $e$ plantões. As principais motivações para as atividades foram a aquisição de maior experiência clínica e um melhor currículo.

\section{A B S T R A C T}

The extra-curricular activities carried out by medical students with the intent to supplement their qualification and increase their practical experience - distant and free from academic control make up the so-called "parallel curriculum". The objective of this paper was to study this "parallel curriculum" of students of the School of Medicine of the Federal University of Minas Gerais (UFMG) during the first semester of 2004. Two hundred and thirty-two students were interviewed applying a structured questionnaire divided into 10 sections. This questionnaire evaluated extracurricular activities such as: service in on-duty infirmaries and out-patient departments; participation in projects, study groups, clinical discussion groups; extension activities and publications. Each student answered with regard to the current semester (the first semester of 2004) and to the previous one, (the second semester of 2003). Results showed the "parallel curriculum" to be a reality for most of the students: $82.5 \%$ developed extra-curricular activities, with a mean of 3.4 per student, dedicating on the average 8.2 hours per week to these activities. Extension activities ranged in the first place, followed by participation in projects and duty service. The main motivations for developing these activities were achieving more practical experience and improving the curriculum. 


\section{INTRODUÇÃO}

A educação tem sido tradicionalmente descrita, de maneira otimista, como um processo de aperfeiçoamento, de desenvolvimento, de libertação e de igualdade social das pessoas.

A partir da década de 1970, visões críticas têm observado a educação sob novos ângulos e abalado fortemente as visões otimistas de até então. Elas apontam o sistema educacional como um instrumento de reprodução social e como um mecanismo de manutenção e perpetuação das diferenças sociais e econômicas ${ }^{1,2}$.

Em relação à educação médica, considerada essencialmente e com as características próprias da educação de adultos, seus objetivos são classicamente divididos como de natureza cognitiva (conhecimento), psicomotora (habilidades) e comportamental (atitudes).

Os objetivos cognitivos seriam aqueles ligados à aquisição, elaboração e organização de informações por meio do acesso ao conhecimento existente. Nesse processo o aprendiz refaz, reconstrói e ressignifica o próprio conhecimento.

Os objetivos psicomotores são relacionados à aquisição de habilidades que permitirão ao futuro médico o bom exercício profissional. Incluem desde as habilidades necessárias à relação médico-paciente, até aquelas relacionadas aos procedimentos técnicos envolvidos nas mais diversas especialidades e na extensa e cada vez mais complexa aparelhagem de uso em diagnóstico e tratamento médicos.

Os objetivos comportamentais completam a formação médica. Eles estão relacionados às relações entre pessoas que a atividade médica exige: a relação entre o médico e seus pacientes, e as relações entre o médico, seus colegas e os diversos outros profissionais que comporão as equipes de saúde nas quais ele irá trabalhar ${ }^{3}$.

A palavra "currículo" (curriculum) é de origem latina e significa percurso, carreira, ato de percorrer. Alguns autores citam sua utilização por Platão e Aristóteles para descrever os temas ensinados no periodo clássico da civilização grega. Outros procuram a origem da palavra em alguma universidade européia da Idade Média ou no sistema educacional medieval dos jesuítas ${ }^{4,5}$.

Na literatura da educação, em geral, e no entendimento diário e comum da maioria dos professores e alunos, o termo "currículo" se refere ao conjunto de disciplinas de um curso, geralmente representado por uma "grade" de disciplinas em que se explicitam conteúdos, ementas, créditos, se obrigatórias ou optativas, as respectivas cargas horárias e sua distribuição pelos períodos acadêmicos.
Segundo Koifman ${ }^{4}$, o currículo - incluindo o currículo médico - pode ser entendido de várias maneiras, desde como um mero texto escrito ou uma "grade" de disciplinas e de cargas horárias, até o "tudo" que ocorre na escola ou na universidade. A visão mais focada num desses dois pólos de interpretação pode levar a simplificações ou à tentativa de controlar um infinito número de variáveis que, nos dois extremos, leva à chance de fracasso na tentativa do entendimento das dimensões e utilidades do currículo e da possibilidade de seu contínuo aperfeiçoamento.

Ainda de acordo com a mesma autora, o tema fica ainda mais controverso quando, em 1968, surge a expressão "currículo oculto" e, com ela, a consideração dos profissionais de educação de que certos fatores não prescritos no currículo se combinam para dar um sabor específico à vida da sala de aula "[...] que incide na eficácia do prescrito"4.

$\mathrm{O}$ "currículo nulo" é aquilo que é parte do currículo, mas não tem aplicabilidade nem utilidade aparente, chegando a ser considerado como materiais e conteúdos supérfluos ${ }^{6}$.

O "currículo paralelo" é definido por $\operatorname{Rego}^{7}$ como "o conjunto de atividades extracurriculares que os alunos [de medicina] desenvolvem, subvertendo, na maioria das vezes a estrutura curricular formal estabelecida pela faculdade" e o "estágio extracurricular" como "todas as atividades de prática clínica ou cirúrgica cumpridas pelo aluno sem que esteja sob os auspícios e direção da escola".

Os currículos das escolas médicas norte-americanas, e a partir daí no resto do mundo, tiveram profundas influências do relatório Flexner, publicado em 1910:

\section{[...] de uma maneira geral as propostas decorrentes do relatório Flexner consignaram um modelo de ensino médico cujas principais características foram: sólida formação em ciências básicas nos primeiros anos do curso; pouca ênfase nos aspectos de prevenção $e$ promoção da saúde; valorização da aprendizagem dentro do ambiente hospitalar; organização minuciosa da assistência médica em cada especialidade; recomendação para que o hospital de ensino contasse com número grande de leitos para cada aluno 8,9 .}

Nas últimas décadas projetos, encontros e conferências internacionais e congressos mundiais de educação médica e no Brasil, a Abem (Associação Brasileira de Educação Médica), a Fepafem (Federação Pan-Americana de Faculdades e Escolas Médicas), o CFM (Conselho Federal de Medicina), a Cinaem (Comissão Interinstitucional Nacional 
de Avaliação das Escolas Médicas), os projetos IDA e UNI, financiados pela Fundação Kellogg, e outras entidades de classe e de educação médica têm proposto diversos projetos e resoluções para efetuar modificações no ensino médico, tendo em vista uma medicina mais integral e melhor atendimento de saúde da população.

Nessa mesma linha, destacam-se o movimento de reforma sanitária e a promulgação da Constituição de 1988 com a consagração da saúde como direito de todos e dever do Estado, a criação do SUS (Sistema Único de Saúde) e a criação da estratégia do PSF (Programa de Saúde da Família).

Nos primeiros anos do século 21, são promulgadas as diretrizes curriculares dos cursos da área da saúde e do curso médico, que oferecem a oportunidade de se criar um novo paradigma na formação do médico, com ênfase numa formação ética, generalista, crítica, humanista e reflexiva, capaz de responder às necessidades de promoção, prevenção, recuperação e reabilitação da saúde da população, com capacidade resolutiva e de auto-atualização, de trabalhar em equipe multiprofissional, com pouca dependência de equipamento e hospital e com uma visão integral dos problemas de saúde do ser humano.

Esse conjunto de iniciativas vem criando as condições para se modificar o modelo flexneriano de formação médica, ainda predominante, considerado superado e insuficiente e responsável por boa parte dos problemas da atenção à saúde das populações, e substituí-lo por um novo modelo, mais integral, humano e menos dependente de equipamento e hospital 1,10,11.

O currículo da Faculdade de Medicina da UFMG, que começou a funcionar em 1911, foi inspirado no da Escola de Medicina do Rio de Janeiro. Na década de 1950, introduziu-se a importante área de Medicina Preventiva, que cresceu de maneira contínua até o currículo atual.

Em 1975, após quatro anos de discussões, começa a funcionar um novo currículo, que prevê, entre outras mudanças, a fusão de disciplinas, adaptação do ambulatório para atendimento em dois turnos, adequação de laboratórios e serviço de radiologia, ampliação do quadro docente, instalação do atendimento extramural. Em 1978, iniciam-se as atividades do Internato do $11^{\circ}$ e $12^{\circ}$ períodos, incluindo a experiência pioneira do Internato Rural ${ }^{12}$.

Segundo Salgado ${ }^{13}$, seriam cinco os pontos centrais do currículo de 1975:

- o ensino médico não pode ser improvisado, amadorístico ou imitativo; em decorrência, foram realizados estudos diagnósticos prévios de 1971 a 1975 e que continuaram posteriormente; - o ensino tem como princípio não perguntar ao professor e ao aluno o que a escola deve ensinar; alunos e professores devem procurar esta resposta na realidade e nas necessidades sociais, às quais a escola deve responder;

- o atendimento das necessidades sociais deve ser avaliado de forma contínua; assim, em vez de surgir um currículo como produto acabado, resulta um processo de desenvolvimento curricular; como conseqüência, o processo para avançar exige seminários de ensino e comissão de avaliação interdisciplinar, como o NAP (Núcleo de Assessoramento Pedagógico); - as habilidades, conhecimentos e atitudes adquiridos principalmente por meio do atendimento ambulatorial precoce de adultos e crianças permitem graduar o médico geral, capaz não apenas de atender à maioria das necessidades de saúde, mas também de se adaptar ao mercado de trabalho atual e futuro; a integração com o sistema assistencial e a inserção precoce do aluno na atividade assistencial são essenciais;

- o novo ensino é adequado não apenas à realidade de saúde, mas à realidade econômica do Brasil; exige pouco investimento de capital, exceto em infra-estrutura, e se concentra na utilização de recursos humanos.

Mais recentemente, a Faculdade de Medicina da UFMG foi selecionada, em 2002, para o programa Promed, que é uma proposta de apoio às escolas médicas que queiram, voluntariamente, adequar seus processos de ensino, de produção de conhecimento e de serviços às necessidades do sistema de saúde do País. O objetivo é estimular as escolas médicas a buscarem excelência técnica e relevância social ${ }^{14}$.

Atualmente, a "grade" curricular dos alunos do curso médico prevê uma média de 30 horas de atividades semanais, além de estudos individuais, em grupo, trabalhos, GDs, etc. Nossa experiência de professor mostra que não é incomum encontrar alunos cumprindo um, dois ou até três plantões de 24 horas semanais, nos mais diferentes regimes de influências éticas, técnicas e de comportamento, em hospitais públicos, privados, clubes e outros locais. Também participam das atividades de rotina de um sem-número de enfermarias, ambulatórios, corridas de leitos, grupos de estudos e de raciocínio clínico, projetos de ensino, extensão e pesquisa, e inumeráveis cursos, palestras, simpósios, jornadas acadêmicas e tantas outras atividades de educação continuada.

Nessas atividades, os alunos utilizam seus horários de refeições, fins de semana, férias e, em muitos casos, com franca superposição de seus compromissos curriculares, num claro malabarismo de horários, matam uma aula aqui, saem mais cedo de um plantão ali, comprometendo os seus já escassos momentos de repouso, lazer, atividade física e aquisição e ampliação de conhecimentos em áreas não médicas. Assim se configura um verdadeiro currículo paralelo, eqüidistante e livre de controles acadêmicos, ao currículo formal, o já mencionado "currículo paralelo". 
Quais seriam os motivadores desse comportamento? Seria desilusão ou desconfiança em relação ao modelo de currículo de 1975? Seria a convicção, por parte dos alunos, da inadequação do currículo ao mercado de trabalho médico atual, que ainda privilegia as especialidades e subespecialidades e a medicina baseada em exames e em alta tecnologia? Seriam as necessidades de aquisição de habilidades e atitudes que o currículo formal não permite? Seria a remuneração? Quem sabe a aquisição de um bom curriculum vitae para disputar as provas de residência médica? Seria um misto de todas elas? E a supervisão e qualificação dos supervisores dessas atividades? Quanto tempo os alunos estão empregando nessas atividades? Onde os alunos preferencialmente estão exercendo as atividades? Um melhor entendimento destas indagações foi um dos principais motivadores do presente estudo.

\section{MATERIAL E MÉTODOS}

Foi realizado estudo transversal, em 2004, dos alunos do ciclo profissional do curso médico da Faculdade de Medicina da UFMG. Este ciclo é composto de oito períodos (5o ao $12^{\circ}$ ) com aproximadamente 160 alunos cada. Selecionou-se uma amostra probabilística dos alunos dos períodos pares $\left(6^{\circ}, 8^{\circ}\right.$, $10^{\circ}$ e $12^{\circ}$ ), matriculados no primeiro semestre de 2004, na Faculdade de Medicina da UFMG. Para o cálculo do tamanho da amostra, foram utilizados como parâmetros uma prevalência média estimada de atividades de currículo paralelo entre estudantes de $70 \%$, uma precisão de $5 \%$ e um nível de confiança de $95 \%$. Considerando-se uma perda aproximada de $10 \%$, entre recusas e alunos não encontrados, foi definido um número total de 243 alunos a serem entrevistados.

A amostragem foi sistemática. Definiu-se uma fração amostral $\mathrm{k}=3$. A primeira unidade amostral foi sorteada entre os nove primeiros alunos da lista. A seguir, percorreu-se a lista para seleção de cada k-ésima unidade consecutiva. Dessa forma, foram sorteados 59 alunos do $6^{\circ}$ período (37,1\% dentre os 159 deste período), 61 do $8^{\text {o }}$ período (36,7\% do total de 166), 62 do $10^{\circ}$ (correspondendo a 37,1\% do total de 167 alunos) e 61 alunos do 12 o período (35,9\% do total de 170 alunos matriculados).

O principal instrumento de pesquisa foi um questionário estruturado formado por dez seções. Cada estudante sorteado respondeu sobre o seu período atual (primeiro semestre de 2004) e sobre o período anterior (cursado no segundo semestre de 2003). Dessa forma, foi possível obter informação sobre os oito períodos que compõem o ciclo profissional do curso médico. Foi realizado um "teste piloto" antes da aplicação dos questionários definitivos. Foram sorteados seis alunos do $5^{\circ}$, $7^{\circ}, 9^{\circ}$ e $11^{\circ}$ períodos, totalizando 24 alunos.
O questionário foi formado por dez seções: a seção 1 (informações gerais) registrava as informações demográficas e sociais dos alunos; a seção 2 (atividade extracurricular geral) visava à simples informação da presença de atividades extracurriculares nas áreas de plantão, enfermaria, ambulatório, projetos, grupos de estudo, grupos de raciocínio clínico e de extensão e publicações (a resposta positiva em qualquer uma dessas áreas permitia aos entrevistadores planejar a entrega dos questionários específicos que iriam detalhar cada atividade); as seções de 3 a 9 visavam às atividades detalhadas dos plantões (seção 3), enfermarias (seção 4), ambulatórios (seção 5), projetos de ensino, pesquisa e extensão (seção 6), grupos de estudo (seção 7), grupos de raciocínio clínico (seção 8) e de cursos de extensão e publicações (seção 9); a seção 10 permitia comentários livres do aluno sobre o tema das atividades extracurriculares.

A seção 1 (informações gerais) e a seção 10 (comentários livres do aluno) foram respondidas apenas uma única vez por cada aluno da amostra. As seções de 2 a 9 foram respondidas sobre as atividades extracurriculares do período "atual" que o aluno cursava (1ํomestre de 2004) e em relação àquelas do período imediatamente anterior. $\mathrm{O}$ questionário foi aplicado nos meses de maio e junho de 2004, e os resultados foram analisados pelo programa Epi-Info 6 .

A equipe de pesquisadores/entrevistadores foi formada por quatro acadêmicos do oitavo período de Medicina e pelo autor do trabalho. Dois dos acadêmicos foram contemplados com seis meses de bolsas patrocinadas pelo projeto Recriar, de Mudança Curricular da Faculdade de Medicina. Os outros dois participaram como voluntários.

O projeto, incluindo o "termo de consentimento livre e esclarecido", foi apresentado, previamente, à comissão de ética em pesquisa em seres humanos da UFMG, tendo sido aprovado sem ressalvas. Aos alunos da amostra, que concordaram em participar da pesquisa, foi apresentado o termo de consentimento livre e esclarecido, que foi lido, assinado e arquivado em separado.

Do total de 243 alunos selecionados na amostra, foram entrevistados 232. Ocorreram somente $4,5 \%$ de perdas ( $\mathrm{n}=$ $11)$, principalmente devido a recusas $(n=8)$.

\section{RESULTADOS}

O presente trabalho faz parte da tese de doutorado do autor. Foram colhidas informações sobre alguns comportamentos dos alunos - como uso de fumo e álcool, atividades esportivas, culturais, conhecimento de línguas estrangeiras -, que não tinham ligação direta com o tema, 
mas que poderiam compor uma imagem mais completa das características dos alunos.

Os resultados serão apresentados em tabelas e de forma condensada, para maior simplicidade e compreensibilidade.
Em virtude de questões de espaço, algumas informações, não relacionadas diretamente aos objetivos atuais, não serão apresentadas neste trabalho, mas em forma de outras publicações específicas.

TABELA 2

Variáveis demográficas e sociais da amostra dos alunos da Faculdade de Medicina da UFMG, Belo Horizonte, 2004

\begin{tabular}{|c|c|c|}
\hline Variável & $\mathrm{n}$ & $\%$ \\
\hline \multicolumn{3}{|l|}{ Idade (anos) } \\
\hline 20 a 24 & 147 & 64,0 \\
\hline 25 a 29 & 81 & 35,4 \\
\hline 30 ou mais & 2 & 0,8 \\
\hline \multicolumn{3}{|l|}{ Sexo } \\
\hline Masculino & 138 & 59,5 \\
\hline Feminino & 94 & 40,5 \\
\hline \multicolumn{3}{|l|}{ Naturalidade } \\
\hline Belo Horizonte & 117 & 50,4 \\
\hline Interior de Minas & 93 & 40,1 \\
\hline Outras cidades & 22 & 9,5 \\
\hline \multicolumn{3}{|l|}{ Estado civil } \\
\hline Solteiro & 225 & 97,0 \\
\hline Casado & 6 & 2,6 \\
\hline Outros & 1 & 0,4 \\
\hline \multicolumn{3}{|l|}{ Número de filhos } \\
\hline Nenhum & 228 & 98,3 \\
\hline Um & 4 & 1,7 \\
\hline \multicolumn{3}{|l|}{ Profissão do pai } \\
\hline Engenheiro & 46 & 19,8 \\
\hline Médico & 32 & 13,8 \\
\hline Aposentado & 30 & 12,9 \\
\hline Outras & 124 & 53,5 \\
\hline \multicolumn{3}{|l|}{ Escolaridade do pai } \\
\hline Primeiro grau & 32 & 13,8 \\
\hline Segundo grau & 48 & 20,7 \\
\hline Terceiro grau/pós-graduação & 152 & 65,5 \\
\hline \multicolumn{3}{|l|}{ Profissão da mãe } \\
\hline Professora & 50 & 21,5 \\
\hline Do lar & 49 & 21,1 \\
\hline Aposentada & 23 & 9,9 \\
\hline Outras & 110 & 47,5 \\
\hline \multicolumn{3}{|l|}{ Escolaridade da mãe } \\
\hline Primeiro grau & 17 & 7,3 \\
\hline Segundo grau & 81 & 34,9 \\
\hline Terceiro grau/pós-graduação & 134 & 57,8 \\
\hline
\end{tabular}


TABELA 3

Número absoluto e percentual de presença de atividades do "currículo paralelo", por periodo, da amostra dos alunos do curso médico da UFMG, Belo Horizonte, 2004

\begin{tabular}{ccc}
\hline Período & $\mathrm{n}$ & $\%$ \\
\hline $5^{\circ}$ & 41 & 69,5 \\
$6^{\circ}$ & 44 & 74,6 \\
$7^{\circ}$ & 51 & 87,9 \\
$8^{\circ}$ & 45 & 77,6 \\
$9^{\circ}$ & 49 & 86,0 \\
$10^{\circ}$ & 54 & 94,7 \\
$11^{\circ}$ & 51 & 87,9 \\
$12^{\circ}$ & 48 & 82,8 \\
\hline Totais & 383 & 82,5 \\
\hline
\end{tabular}

TABELA 1

Distribuição absoluta e percentual dos tipos de motivação, isolados ou associados, para as atividades do "currículo paralelo", da amostra dos alunos do curso médico da UFMG, Belo Horizonte, 2004

\begin{tabular}{lcc}
\hline Tipo de motivação & $\mathrm{n}$ & $\%$ \\
\hline Aquisição de prática clínica & 211 & 90,7 \\
Currículo & 143 & 61,6 \\
Remuneração & 81 & 34,9 \\
Participação em equipe & 77 & 33,2 \\
Facilitar entrada em Residência Médica & 60 & 25,9 \\
Conseguir emprego após a formatura & 14 & 6,0 \\
Outras & 21 & 9,1 \\
\hline
\end{tabular}


QUADRO 1

Resumo das atividades do "currículo paralelo" da amostra dos alunos do curso médico da UFMG, Belo Horizonte, 2004

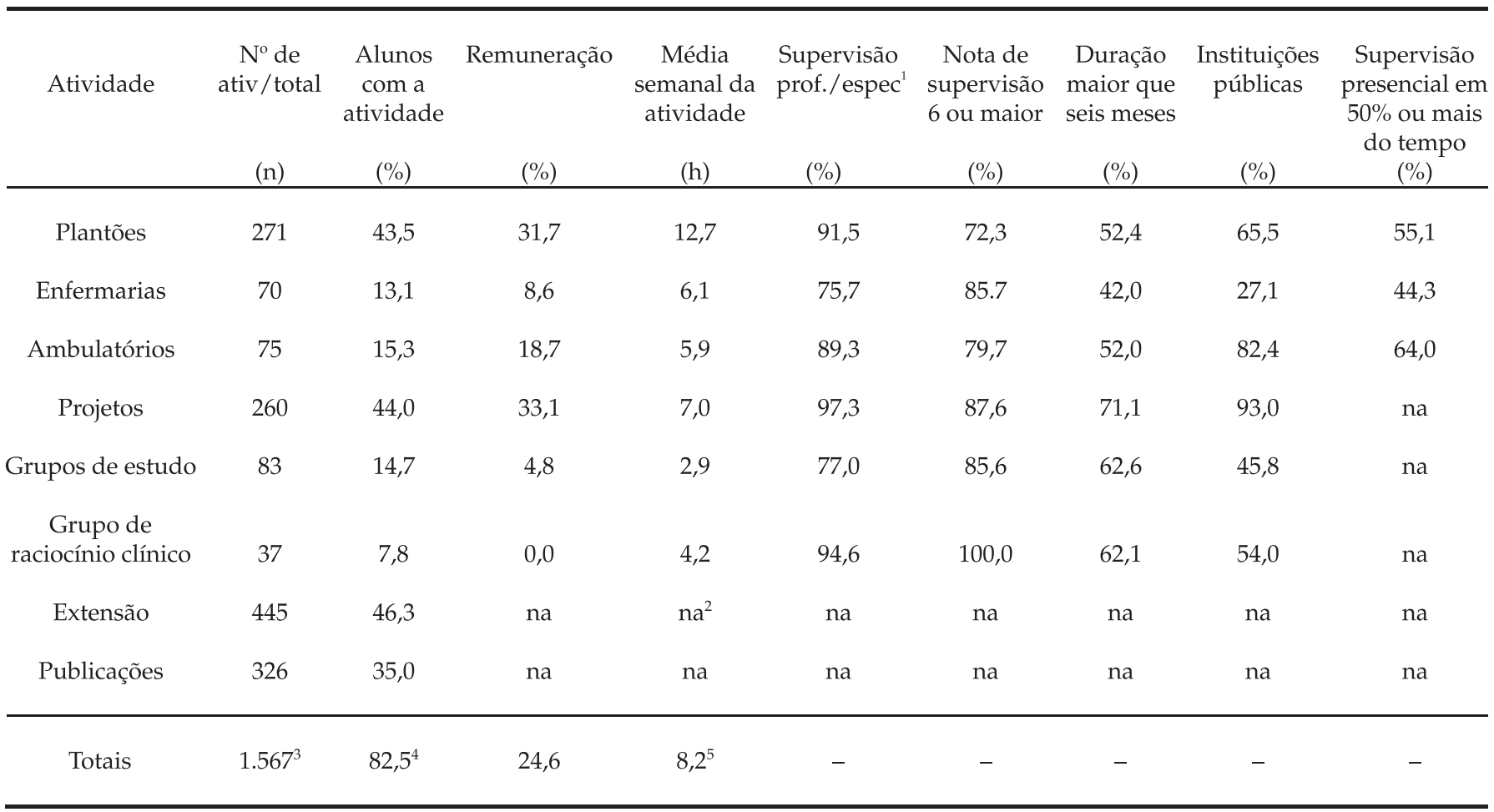

1. prof. $/$ espec. $=$ professores $/$ especialistas

2. na $=$ não se aplica

3. A média de atividades por aluno foi de 3,4

4. Média geral da participação dos alunos da amostra nas atividades

5. Média horária semanal média de todas as atividades

\section{DISCUSSÃO}

O presente estudo teve como objetivo geral a avaliação quantitativa do "currículo paralelo" dos estudantes de Medicina da UFMG.

O possível "viés do entrevistador", pelo fato de os entrevistadores serem estudantes de Medicina e colegas dos entrevistados, foi minimizado com a estratégia de entregar os cadernos dos questionários aos alunos entrevistados com um mínimo de interferência, e seu preenchimento ser feito direta e exclusivamente pelo entrevistado.

Já o "viés de memória" foi considerado pouco significativo porque as respostas se referiam ao semestre atual do aluno e ao semestre imediatamente anterior.

$\mathrm{Rego}^{7}$, em sua revisão do tema na literatura da educação médica, mostra que as atividades dos estudantes de Medicina que podem ser reconhecidas como de "currículo paralelo" são bastante antigas, havendo referências a elas desde a década de 1920 no Rio de Janeiro, principalmente em hospitais públicos com serviços de emergência, para alunos dos últimos anos. As atividades extracurriculares também foram identificadas em vários estados, como Rio de Janeiro, São Paulo, Minas Gerais e Rio Grande do Sul.

Um trabalho que merece ser citado é o de Kloetzel ${ }^{15}$, que analisou informações sobre as atividades extracurriculares (o "ensino paralelo", como o autor denomina) de 272 estudantes de Medicina de quatro escolas médicas de São Paulo. O autor registra que, no quarto e quinto anos do curso, dois terços dos alunos já trabalham fora da escola, atingindo $92 \%$ no último ano, com a média de 24 horas semanais de trabalho. O principal motivador seria o desejo de um aprendizado mais apurado. $\mathrm{O}$ autor faz críticas à precariedade da supervisão das atividades e à excessiva ênfase no aprendizado hospitalar em relação ao ambulatório. 
Outro artigo importante é o de Souza ${ }^{16}$, que abordaram a prática dos estágios extracurriculares de acadêmicos de Medicina da UFMG, em 1992. Os resultados mostraram que apenas quatro alunos relataram não ter feito nenhum estágio, e a média de estágios por aluno foi de 3,1. A maioria deles (72\%) foi realizada em especialidades básicas de Clinica Médica, Pediatria, Cirurgia e Ginecologia/Obstetrícia. Os hospitais mais freqüentados foram o João XXIII (Pronto Socorro), a Santa Casa de Belo Horizonte e o Centro Geral de Pediatria (CGP). A principal motivação para a realização dos estágios foi suprir as deficiências do curso e adquirir experiência clínica. Apenas $40 \%$ das atividades foram remuneradas.

Embora existam diferenças nas duas investigações, chamam a atenção as semelhanças em muitas características do "currículo paralelo" dos estudantes de Medicina da UFMG em 1992 e 2004. Nos dois estudos, a maioria dos alunos apresentava atividades extracurriculares, principalmente em hospitais públicos, como João XXIII (principal hospital de pronto socorro de Belo Horizonte), Centro Geral de Pediatria (CGP) e Santa Casa de Belo Horizonte. As especialidades básicas, como Pediatria, Clínica Médica e Cirurgia, foram predominantes nos dois casos. Os principais motivos apresentados em ambos os trabalhos estavam relacionados com aquisição de experiência clínica, e a remuneração teve motivação secundária nas duas situações ${ }^{16}$.

O conceito de "currículo paralelo" não tem uma definição precisa na literatura da educação médica. $\operatorname{Rego}^{7}$, em sua tese de mestrado, o define como "o conjunto de atividades extracurriculares que os alunos [de Medicina] desenvolvem, subvertendo, na maioria das vezes, a estrutura curricular formal estabelecida pela faculdade", e o estágio extracurricular como "todas as atividades de prática clínica ou cirúrgica cumpridas pelo aluno sem que esteja sob os auspícios e direção da escola", embora na sua descrição inclua basicamente as atividades de emergência, CTI/UTI/unidade coronariana, Ginecologia e Obstetrícia e outras, deixando ver que, na sua concepção, as atividades assim chamadas do "currículo paralelo" se superpõem ao que chama de atividades de estágios extracurriculares, que são realizados basicamente em hospitais.

Por outro lado, Araújo ${ }^{5}$, em Uberlândia, amplia o conceito do que chama de atividades extracurriculares incluindo monitorias, acompanhamento de profissionais em seu ambiente de trabalho, plantões em serviço de saúde privada, projetos de extensão, participação no centro de informações toxicológicas, plantões em serviço de saúde pública, programa especial de treinamento (PET) e projetos extramuros. Entretanto, se refere a essas atividades como parte da realidade. Constituem o chamado "currículo paralelo" e podem representar uma importante fonte de aprendizagem, mas, por outro lado, podem distorcer a formação médica.

Já Valença ${ }^{17}$, na Faculdade de Ciências Médicas de Pernambuco (FCM-UPE), considerou como atividades do "currículo paralelo" aquelas realizadas pelos estudantes simultaneamente ao currículo oficial e ele as agrupou em estágios de pesquisa, monitoria de ensino, e serviços de atenção médica.

Também são usadas outras denominações para o "currículo paralelo" - "ensino paralelo", "currículo informal", "currículo clandestino" ou "currículo pessoal" -, com significações mais ou menos semelhantes $7,13,15,18$.

Em nosso estudo na Faculdade de Medicina da UFMG, optamos por definir as atividades do "currículo paralelo" como "atividades na área médica e afins e que não geram créditos para serem integralizados no currículo do curso médico do aluno e não irão fazer parte do histórico escolar". Operacionalmente, ampliamos o escopo de atividades que poderiam fazer parte do "currículo paralelo" e incluímos no estudo, além das práticas extracurriculares mais "tradicionais" e reconhecidas, como as de plantão, enfermaria, ambulatório e projetos, outras também intensamente utilizadas e que consideramos ter claro potencial e significativa importância para a formação dos alunos, como as de grupos de estudo, grupos de raciocínio clínico, extensão e publicações.

A análise dos dados da literatura sobre o tema "currículo paralelo" parece não deixar dúvidas de que a principal motivação dos estudantes é a "aquisição de prática clínica" ou a "experiência clínica" ou "aperfeiçoar a clínica". Os alunos freqüentemente se referem à possibilidade de entrar em contato com grande número de pacientes agudos, das mais diversas patologias e com grande autonomia de atuação, o que não acontece nos hospitais universitários em seus estágios curriculares, que apresentam forte viés de pacientes crônicos e de patologias raras $5,7,17$.

$\mathrm{Rego}^{7}$, em seu trabalho pioneiro, faz uma extensa avaliação das motivações dos estudantes de Medicina para a antiga e generalizada atividade extracurricular, caracterizada de maneira resumida com a explicação de "aquisição de prática clínica". O autor as coloca no patamar da necessidade de socialização do estudante de Medicina, do desenvolvimento de uma auto-imagem profissional e do ideal de serviço médico para sua plena atuação como futuro profissional médico e a partir daí obter pleno usufruto das vantagens econômicas e de status social, entre outras, da profissão. 
Adquirir um bom currículo é outra motivação importante e alegada com freqüência nas pesquisas. Na opinião dos alunos, o bom currículo facilitaria a entrada nas residências médicas, já que boa parte delas valoriza, no processo de seleção, as experiências extracurriculares mais tradicionais, como plantões, enfermarias, cursos e monitorias. Também a publicação de trabalhos, conhecimento de línguas estrangeiras e outras ações que no nosso conceito poderiam ser caracterizadas como do "currículo paralelo" são valorizadas, de maneira variada, pelos processos de seleção das residências médicas.

Já a parte financeira, considerada em alguns trabalhos como importante ou a mais importante motivação para tal prática, parece não ser o caso, já que aparece em terceiro lugar nos estudos citados $5,7,17$ e também no nosso. Em sintonia com essa idéia, verifica-se que a maioria dos alunos não recebe remuneração por suas atividades e provém de famílias de classe média alta, que podem perfeitamente financiar os estudos e a manutenção de seus filhos ${ }^{1}$.

Esses comentários podem ser verificados na Tabela 1, onde, no item "motivações para a prática do currículo paralelo", realmente predominam a "prática clínica/ conhecimento" e o "currículo" nos estudos citados, vindo apenas em terceiro lugar a "remuneração".

Em nível internacional, há pouca ou nenhuma referência à existência de um "currículo paralelo" com atividades extracurriculares ligadas a plantões, enfermarias e outras, relacionadas com o cuidado direto de pacientes.

Entretanto, encontraram-se algumas experiências, como, por exemplo, a de Grupos de Aprendizado do Estudante de Medicina, do Colégio de Medicina da Universidade de Vermont, "cujo objetivo é introduzir os estudantes nos conceitos e habilidades da colaboração, dinâmica de grupo, aprendizado independente e liderança em medicina", organizados em pequenos grupos interativos de aprendizado de seis estudantes e com a colaboração de professores, e considerados como atividade extracurricular ${ }^{19}$.

Também a Escola de Medicina de Monte Sinai relata a criação de um escritório para estimular a participação e gerenciar as oportunidades de treinamento em pesquisa para estudantes de Medicina em atividades curriculares e extracurriculares, inclusive objetivando que eles se iniciem precocemente nas atividades e as mantenham após a formatura, ajudando a diminuir o crescente problema americano da queda do número de cientistas-clínicos ${ }^{20}$.

Uma interessante publicação da Escola de Medicina da Universidade de Zagreb mostra a participação em atividades extracurriculares dos estudantes de Medicina daquela escola médica durante a guerra na Croácia e na vizinha Bósnia e Herzegovina.

Os estudantes se envolveram intensamente em trabalhos relacionados com os aspectos médicos da guerra, como organização de cursos de ressuscitação, primeiros socorros e direitos humanos, coleta de documentação médica das vitimas da guerra, ajuda humanitária aos refugiados, principalmente crianças, atividades de comunicação e promoção da paz, ajuda psicológica e médica à população no periodo pós-guerra, e até participaram das equipes médicas na região das batalhas.

A ação dos estudantes nas atividades extracurriculares relacionadas com sua atividade profissional e com a guerra foi considerada, pelos autores do trabalho, como extremamente benéfica para o bem-estar psicológico e os estudos dos alunos, bem como para o processo de reconstrução da região ${ }^{21}$.

A distribuição das variáveis demográficas e sociais da amostra revelou características semelhantes às de outros estudos (Tabela 2). Os alunos são jovens, com idades predominantemente entre 20 e 29 anos, com número reduzido acima de 30 anos. Predomina a presença do sexo masculino, com 59,5\% no presente estudo. Existe alguma variação em outros estudos: 52,2\% em Rego 7 , 57,3\% em Araújo ${ }^{5}$ e 54,0\% em Valença ${ }^{17}$. Uma minoria de apenas 2,6\% alunos é casada. Não há muita diferença nos outros estudos: $4,5 \%$ no quarto ano e 9,5\% no sexto ano em $\operatorname{Rego}^{7}, 15,6 \%$ em Araujo e 6\% em Valença ${ }^{17}$. O número de filhos também é reduzido nos quatro estudos citados. No nosso, apenas 1,7\% dos alunos se refere a um filho, o que reforça os resultados da pouca motivação financeira para as atividades do "currículo paralelo".

A naturalidade dos alunos é representada por mais de 90\% de nascidos em Belo Horizonte e cidades do interior de Minas (Tabela 2). Na UFRJ, mais de $80 \%$ dos alunos eram naturais do próprio estado do Rio de Janeiro7. Já na UFU, $66,7 \%$ dos alunos eram procedentes de Uberlândia e outras cidades de Minas Gerais, mas com significativos 17,7\% procedentes de Goiás ${ }^{5}$. Na FCM-UPE, 96,1\% dos estudantes eram procedentes da Região Nordeste, com 75,14\% procedentes do estado de Pernambuco ${ }^{17}$. As diferenças significativas, nesse aspecto, mostram características que representam as diversas realidades loco-regionais das escolas médicas. Vale registrar que em alguns dos estudos citados é utilizada a naturalidade do aluno, e noutros, a procedência.

Na questão da escolaridade e profissão do pai e da mãe dos alunos, verifica-se a predominância de pais e mães com terceiro grau e pós-graduação e com profissões tradicionais (Tabela 2). Apenas 13,8\% dos pais e 7,3\% das mães apresentam 
escolaridade correspondente ao primeiro grau, em nosso estudo. A tendência à estratificação sociocultural parece ocorrer a partir das décadas de 1950 e 1960, levando a que os médicos de hoje sejam predominantemente filhos de classe média urbana, de profissionais liberais, com tendência a uma crescente alta escolarização dos pais e, de maneira ainda mais acelerada, das mães 22 .

No presente estudo, não foram avaliadas as variáveis econômicas dos estudantes. Entretanto, Ferreira ${ }^{1}$, ao estudar o perfil socioeconômico de estudantes de Medicina da UFMG, do quinto período e do internato, mostrou que seu perfil socioeconômico é alto: renda familiar entre 10 e 50 salários mínimos em dois terços dos casos. Em apenas 12\%, a renda era inferior a 10 salários, contra 37,2\% da média da UFMG. O padrão de renda da família dos estudantes de Medicina da UFMG também é superior à média das Instituições Federais de Ensino Superior (Ifes), mostrando um perfil socioeconômico bastante elevado. $\mathrm{O}$ mesmo acontece com o nível de escolaridade familiar, compatível com a origem dos estudantes, de parcelas da classe média alta e da intelectualidade ${ }^{1}$.

A Tabela 3 mostra a distribuição das atividades globais do currículo paralelo do quinto ao $12^{\circ}$ períodos. Há intensa atividade, com 69,5\% dos alunos já participando no quinto periodo. Há aumento progressivo da participação, que culmina, no $10^{\circ}$ período, com $94,7 \%$ deles tendo ações extracurriculares. Já no $11^{\circ}$ e $12^{\circ}$ períodos, a participação dos alunos cai um pouco, com $87,9 \%$ e $82,8 \%$, respectivamente. A média geral da participação foi de $82,5 \%$.

A Tabela 1 apresenta as motivações referidas pelos alunos em sua participação nas atividades do "currículo paralelo". As principais são a aquisição de prática clínica, em 90,7\% dos casos, a aquisição de um melhor currículo, em 61,6\%, e, notavelmente, a remuneração vem em terceiro lugar com 34,9\%. As mesmas características são encontradas em outros estudos (Rego ${ }^{7}$, Araujo $^{5}$ e Valença ${ }^{17}$ ).

O Quadro 1 resume os resultados das diversas atividades compiladas como pertencentes ao "currículo paralelo", inclusive as de extensão e publicações, que foram avaliadas globalmente. A análise desse quadro mostra que são atividades intensivas, abrangendo um grande leque de opções e sendo realizadas pela maioria dos estudantes - no caso da UFMG, de $82,5 \%$. Na UFRJ, foram $76,7 \%$, na UFU, $100,0 \%$, e na FCM UPE, $80,0 \% 5,7,17$.

\section{CONCLUSÕES}

Na Faculdade de Medicina da UFMG, a partir do estudo realizado envolvendo a amostra dos alunos do $5^{\mathrm{o}}$ ao $12^{\mathrm{o}}$ períodos, podemos concluir que:

- O "currículo paralelo" é presente para a grande maioria dos alunos com $82,5 \%$ deles com atividades. No $10^{\circ}$ período é onde ocorre o maior percentual com $94,7 \%$ de alunos participando. Já o menor percentual é no $5^{\circ}$ periodo com $69,5 \%$;

- As principais motivações para a participação no "currículo paralelo" são a aquisição de prática clínica, a aquisição de um bom currículo, e em terceiro lugar a remuneração;

- A média de atividades do "currículo paralelo" é de 3,4 por aluno e eles dedicam a elas, em média, 8,2 horas semanais;

- A atividade mais presente é a de "extensão" com 46,3\% dos alunos com participação, seguida pelos plantões e projetos;

- A grande maioria dos supervisores do "currículo paralelo" dos alunos foi constituída de professores e médicos especialistas e os alunos na maioria ficaram satisfeitos com a supervisão;

- Os locais onde se realizaram as atividades de plantão, ambulatórios, enfermaria e projetos foram em sua maioria públicos;

- A supervisão na metade das situações foi presencial em $50 \%$ do tempo ou superior.

\section{CONSIDERAÇÕES FINAIS}

As atividades de "currículo paralelo" dos estudantes de medicina são antigas, extensas e acontecem em grande número de faculdades brasileiras (talvez todas?) envolvendo grande parte, senão todos os estudantes e são consideradas normais e naturais, por estudantes, profissionais e professores na busca por complementação da formação e no aumento da experiência clínica dos alunos de Medicina.

A definição de quais atividades fariam parte do "currículo paralelo" varia de autor para autor, não havendo consenso sobre o tema. Alguns consideram apenas atividades clássicas como plantões e atividades em enfermaria. Outros incluem no conceito também atividades em projetos de pesquisa e de ensino.

A proposta do autor é acrescentar a essas atividades, estudos individuais e em grupo (grupos de estudo e raciocínio clínico), de extensão (projetos, cursos e educação continuada) e publicações e talvez outras atividades como estudo de línguas, atividades de política estudantil e mesmo atividades 
nas chamadas medicinas alternativas (acupuntura, homeopatia, plantas medicinais, etc.), todas relevantes para o processo de formação da identidade profissional dos estudantes de Medicina.

A motivação principal para tais atividades é a aquisição de prática clínica e a melhora do currículo, vindo em terceiro lugar a questão econômica. No nosso estudo os estudantes têm boa avaliação das atividades e da supervisão das mesmas, e elas acontecem, na sua maioria em instituições públicas e correspondem a significativo número de horas semanais de atividades.

Há reconhecimento na literatura da educação médica de que as atividades do "currículo paralelo" podem ser relevantes para a formação dos estudantes de medicina o que as colocam como passiveis de serem, integralizadas pelo currículo formal.

\section{REFERÊNCIAS}

1. Ferreira RA. A pediatria da UFMG: inserção na mudança de ensino médico implantada em 1975 e sua relação com o saber (paradigma científico) e a prática médica. Belo Horizonte, MG; 2000. Doutorado [Tese] - Universidade Federal de Minas Gerais.

2. Silva TT. O que produz e o que reproduz em educação: ensaios de sociologia da educação. Porto Alegre: Artes Médicas; 1992.

3. Gonçalves EL. Os objetivos da educação médica. Rev Bras Educ Med. 1998; 22(2-3): 9-18.

4. Koifman L. A teoria de currículo e a discussão do currículo médico. Rev Bras Educ Med. 1998; 22(2-3): 37- 47.

5. Araújo MBJ. Análise das atividades extracurriculares e sua contribuição para a formação dos alunos do curso de medicina da Universidade Federal de Uberlândia. Uberlândia, MG; 1998. Mestrado [Dissertação] Universidade Federal de Uberlândia.

6. Meza BMA, Cepeda RDM. El curriculum nulo e sus diferentes modalidades. Rev Iber Am Educ. [online]. 2001. [capturado 03 ago. 2006]. Disponivel em: http://www.rieoei.org/ deloslectores/220Meza.PDF

7. Rego STA. A prática na formação médica: o estágio extracurricular em questão. Rio de Janeiro; 1994. Mestrado [Dissertação] - Universidade do Estado do Rio de Janeiro.

8. Rodriguez MI. Toma de posición frente a las experiencias evaluativas en educación médica. In: Encuentro Continental de Educación Medica; 1994 out. 10-14; Punta del Este,
Uruguay. Uruguay: OPS/OMS/Universidad de la Republica; 1994. p.151-176.

9. Marsiglia RG. Relação ensino/serviços: dez anos de Integração Docente Assistencial (IDA) no Brasil. São Paulo: Hucitec; 1995. Cáp.1: Histórico das idéias e propostas.

10. Lampert JB. Currículo de graduação e o contexto da formação do médico. Rev Bras Educ Med. 2001; 25(1): 7-19.

11. Lampert JB. Avaliação do processo de mudança na formação médica. In: Marins JJN, Rego S, Lampert JB, Araújo JGC, orgs. Educação médica em transformação: instrumentos para a construção de novas realidades. São Paulo: Hucitec; 2004. p.245-266.

12. Corrêa EJ, Gusmão SNS. 85 anos da Faculdade de Medicina da Universidade Federal de Minas Gerais. Belo Horizonte: Coopmed; 1997. Cáp.: História da Faculdade de Medicina da UFMG.

13. Salgado JA. Contribuição ao estudo da relação entre realidade de saúde e ensino médico. Belo Horizonte, MG; 1981. Doutorado [Tese] - Universidade Federal de Minas Gerais.

14. Associação Brasileira de Educação Médica. PROMED Programa de incentivo às Mudanças curriculares das Escolas Médicas. [online]. [capturado 25 out. 2005]. Disponível em: http://www.abem-educmed.org.br/promed.

15. Kloetzel K. O ensino paralelo da Medicina. In: Federação Pan-Americana de Associações de Faculdades (Escolas) de Medicina; Associação Brasileira de Educação Médica. Anais da VI Conferência Pan-americana de Educação Médica, XIV Congresso Brasileiro de Educação Médica, 1976 nov. 17-19; Rio de Janeiro. Rio de Janeiro: ABEM; 1976. p.669-674.

16. Souza CL, Matias LR, Castro MSM, Souza MSL, Nehmy RM. A prática de estágios extracurriculares de acadêmicos de Medicina da Universidade Federal de Minas Gerais, em 1992. Rev Med Minas Gerais. 1994; 4(3); 9-12.

17. Ribeiro CMP. De estudante de medicina a médico no interior: formação e vida profissional isolada em pequenas cidades de 22 médicos egressos da Universidade Federal de Minas Gerais: de 1978 a 1985. Campinas, SP;1991. Doutorado [Tese] - Universidade Estadual de Campinas.

18. Valença OAA. Currículo paralelo em medicina: o caso da Faculdade de Ciências Médicas de Pernambuco. São Paulo; 1999. Mestrado [Dissertação] - Universidade de São Paulo.

19. Pigeon Y. Medical student learning groups. Acad Med. 2001; 76(5): 503-7. 
20. Zier K, Stagnaro-Green A. A Multifaceted program to encourage medical students' research. Acad Med. 2001; 76(7): 743-7.

21. Gluncic V, Pulanic D, Prka M, Marusic A, Marusic M. Curricular and extracurricular activities of medical students during war, Zagreb University School of Medicine, 19911995. Acad Méd. 2001; 76(1): 82-7.

22. Machado MH. Os médicos no Brasil: um retrato da realidade. Rio de Janeiro: Fiocruz; 1997.
CONFLITO DE INTERESSE:

Declarou não haver.

\section{ENDEREÇO PARA CORRESPONDÊNCIA}

Ari de Pinho Tavares

Rua Bento Nogueira, 135 - Santa Amélia

31555090 - Belo Horizonte - Minas Gerais

E-mail: atavares@task.com.br 